\title{
Pengembangan Media Smart Land Untuk Meningkatkan Kemampuan Berpikir Kreatif Dalam Penerapan 3CM Learning Untuk Peserta didik Sekolah Dasar
}

\author{
Wahyudi $^{1}$, Dian Nuryani ${ }^{2}$, Yohana Setiawan ${ }^{3}$ \\ yudhi@uksw.edu',dnur7264@gmail.com², yohana.setiawan@uksw.edu ${ }^{3}$ \\ Universitas Kristen Satya Wacana Salatiga ${ }^{1,3}$ \\ SDN Pasekan 01 Ambarawa $^{2}$
}

\begin{abstract}
The Development of Smart Land Media To Improve Creative Thinking Skill In 3CM Learning Implementation for Elementary School Students
\end{abstract}

\begin{abstract}
The purpose of this research is to develop and test the validity, practicality, and effectiveness of Smart Land media to enhance creative thinking skills in 3CM Learning for elementary school students.The method of this research is $R \& D$ using ADDIE model, in five steps: 1) analysis, 2) design, 3)development, 4)iImplementation, 5) evaluation. The validity of product test is observed from the expert's assessement using the material and media expert validation sheet instruments. The effectiveness of the product is observed by the one group pretest, post-test, and the result are processed using Paired-Samples T-Test assistance with SPSS 22.0 program. The result of this research suggests Smart Land media learning to enhance creative thinking skills in 3CM Learning for Elementary School students, which is evidently valid from materials and media aspect. Smart Land media is evidently practical from teacher and student evaluation, and also evidently effective based on result of pretest and posttest and Paired Samples T-test.
\end{abstract}

Keywords : Learning Media, Smart Land Media, Creative Thinking, 3CM Learning, Elementary School Student

$\begin{array}{lcc}\text { Article Info } & \\ \text { Received date: } 19 \text { November } 2021 & \text { Revised date: } 6 \text { Januari } 2022 & \text { Accepted date: } 27 \text { Januari } 2022\end{array}$

\section{PENDAHULUAN}

Salah satu tujuan yang ingin dicapai dalam pendidikan Indonesia adalah mengembangkan potensi peserta didik menjadi manusia yang kreatif (Republik Indonesia, 2003). Mengembangkan kemampuan kreatif peserta didik juga menjadi salah satu alasan perubahan kurikulum nasional Indonesia dari Kurikulum 2006 menjadi Kurikulum 2013. Selain kedua alasan tersebut, kreatif juga merupakan salah satu komponen utama pendidikan abad ke-21 (Kawuryan et al., 2018; Navarrete, 2013; Sternberg, 2005, 2012; Tindowen et al., 2017).

Oleh sebab itu, kurikulum kontemporer yang mengacu pada komponen utama pendidikan abad ke-21 menekankan pada pengembangan kemampuan berpikir kreatif yang merupakan hasil dari kemampuan kreatif peserta didik (Rohmatin Apriliani \& Suyitno, 2016; Sternberg, 2006; Sternberg \& Sternberg, 2016; Vale \& Barbosa, 2015). Kemampuan berpikir kreatif mempunyai beberapa aspek yaitu aspek kelancaran (fluency), kebaruan (novelty), dan elaborasi (elaboration) (Fatah et al., 2016; Maharani et al., 2017; Moma, 2017; Siswono, 2010, 2011). Kemampuan berpikir kreatif inilah yang akan membentuk aktivitas kreatif yang dinamakan kreativitas. Kreativitas inilah yang akan mengarahkan pada perolehan wawasan baru, pendekatan baru, perspektif baru, atau cara baru (Istiqomah et al., 2017). Peningkatan kemampuan berpikir kreatif akan mendorong meningkatnya daya kreativitas peserta didik (Fatah et al., 2016; Maharani et al., 2017; Moma, 2017; Siswono, 2010, 2011).

Daya kreativitas peserta didik menjadi sesuatu yang penting (Kadir \& Satriawati, 2017; Lev \& Leikin, 2013; Nuha et al., 2018) dan perlu ditumbuhkembangkan termasuk di Sekolah Dasar (SD). Kreatifitas merupakan kualitas integrasi dari seseorang dan menjadi modal seseorang untuk berkarya (Khairullina et al., 2016). Kreatifitas muncul karena adanya kesempatan untuk melakukannya (Wahyudi et al., 2021). Kreatifitas muncul karena ada suasana, lingkungan dan komunitas yang dikondisikan 
untuk melakukan sesuatu yang kreatif (Cahyati et al., 2018; C.-E. Huang, 2020; C.-H. Huang, 2016). Kondisi ini menuntut kemampuan seorang pengajar untuk mengembangkan kemampuan berpikir kreatif peserta didik yang berimplikasi pada aktivitas kreatif (kreativitas) (Trnova \& Trna, 2014). Pengajar tidak hanya fokus pada menyelesaian materi, tetapi bagaimana mengembangkan kemampuan berpikir kreatif sehingga kreativitas peserta didik meningkat (As'ari et al., 2019). Dengan kemampuan berpikir kreatif tersebut seseorang akan menghasilkan kreatifitas yang mengarah pada perolehan wawasan baru, pendekatan baru, perfektif baru atau cara baru dalam memahami suatu masalah yang meliputi aspek keluwesan, kebaruan dan elaborasi (Wahyudi et al., 2019).

Salah satu cara untuk mewujudkan hal tersebut adalah menerapkan model pembelajaran yang memberi kesempatan peserta didik mengembangkan kemampuan berpikir kreatif yang mendorong tumbuhkan kreativitas. Salah satu model pembelajaran yang dapat diterapkan adalah 3CM learning. Model 3CM (Cool-Critical-Creative-Meaningful) learning mulai dikembangkan tahun 2018 dan mulai dipublikasikan tahun 2019. Model 3CM learning merupakan model pembelajaran yang memberikan kesempatan belajar dengan melibatkan kerja otak kiri dan kanan. Model pembelajaran yang tidak hanya memberikan kesempatan peserta didik berpikir menggunakan logika (otak kiri), tetapi juga memberikan kesempatan peserta didik mengembangkan kreativitasnya dengan memaksimalkan kerja otak kanan sebagai sumber intuisi, inisiatif, seni dan kreatifitas. Kegiatan pembelajaran terdiri dari empat aspek yaitu Cool, Critical, Creative, Meaningful. Kegiatan belajar dilakukan dalam empat tahapan belajar yaitu Saatnya Bermain dan Tantangan (Cool), Saatnya Mengkritisi (Critical), Saatnya Berkreasi (Creative) dan Saatnya Merefleksi dan Mengambil Makna (Meaningful).

Salah satu karakteristik model 3CM learning adalah memberikan peluang peserta didik merasakan suasana belajar asik tetapi menantang (Cool (Bermain dan Tantangan)). Fase ini menjadi kunci dari kegiatan belajar berikutnya sesuai sintaks model 3CM learning. Peserta didik diajak berpikir kritis dan kreatif dalam suasana asik dan menyenangkan, tetapi harus memberi tantangan. Untuk mendukung fase ini diperlukan beberapa sarana dan juga media agar peserta didik dapat belajar dalam situasi yang asik dan menantang, salah satunya adalah dengan game.

Game yang akan dikembangkan diperuntukan untuk peserta didik di Sekolah Dasar. Untuk itu pengembangan game ini disesuaikan dengan karakteristik peserta didik di Sekolah Dasar. Game yang akan dikembangkan diberi nama Smart Land yang menggabungkan antara media Bord Game dan Puzzle. Dengan fasilitas game ini akan memberi kesempatan peserta didik dapat bermain (asik) tetapi ada aktivitas yang memberikan tantangan kepada mereka karena ada misi yang harus diselesaikan. Dengan mekanisme kegiatan ini maka akan memberi kesempatan peserta didik masuk fase 1 dalam model 3CM learning yaitu Cool (Bermain dan Tantangan).

\section{KAJIAN PUSTAKA}

\section{Media Pembelajaran}

Media pembelajaran adalah media yang digunakan dalam pembelajaran sebagai perantara pesan berupa materi pelajaran kepada peserta didik (Rusman, 2017). Media pembelajaran berupa alat bantu proses pembelajaran untuk menyampaikan materi pelajaran (Republik Indonesia, 2016).

Media pembelajaran adalah sarana atau alat bantu pendidikan yang digunakan sebagai perantara dalam proses pembelajaran untuk meningkatkan efektifitas dan efisiensi dalam mencapai tujuan pengajaran (Sanaky, 2013). Media sebagai komponen strategi pembelajaran merupakan wadah dari pesan yang ingin disampaikan kepada penerima pesan, materi yang ingin disampaikan berupa pesan pembelajaran, dan tujuan yang hendak dicapai adalah terjadinya proses belajar (Al-Tabany, 2011)

Berdasarkan pendapat-pendapat di atas, dapat disimpulkan bahwa media pembelajaran merupakan perantara, sarana atau alat bantu yang dapat digunakan dalam proses pembelajaran yang berupa wadah dari pesan yang ingin disampaikan kepada peserta didik guna meningkatkan efektifitas dan efisiensi dalam mencapai tujuan pembelajaran.

\section{Media Board Game}

Board game adalah permainan yang dilakukan di atas papan dengan jumlah pemain minimal dua orang (Danarty, 2010). Sejalan dengan ungkapan forum board game Indonesia yang mengemukakan bahwa board game adalah suatu permainan non-elektronik yang memakai papan sebagai komponen utamanya, serta komponen lainnya seperti kartu token, uang kertas, dan lain sebagainya (Limantara et al., 2015). Board game adalah jenis permainan dimana alat-alat atau bagian- 
Pengembangan Media Smart Land Untuk Meningkatkan Kemampuan Berpikir Kreatif Dalam

Penerapan 3CM Learning Untuk ... (Wahyudi, Dian Nuryani, Yohana Setiawan)

bagian permainan ditempatkan, dipindahkan, atau digerakkan pada permukaan yang telah ditandai atau dibagi-bagi menurut seperangkat peraturan dan permainan mungkin didasarkan pada strategi murni, kesempatan, atau campuran dari keduanya dan biasanya memiliki tujuan yang harus dicapai seseorang (Soebagio et al., 2015).

Berdasarkan pendapat-pendapat di atas, dapat disimpulkan bahwa board game adalah permainan yang dilakukan dengan jumlah pemain minimal dua orang dengan komponen utama permainan adalah papan, komponen lainnya seperti kartu token maupun uang kertas, dan permainan ini memiliki seperangkat peraturan serta tujuan yang harus dicapai.

Berdasarkan jenisnya, board game menurut Bell (Limantara et al., 2015) dikategorikan sebagai berikut:

\section{Strategi Board Game}

Permainan ini mengutamakan keahlian dan kepandaian dari si pemain sendiri, salah satu contohnya adalah permainan catur.

2. German-Style Board Game atau Eurogames

Permainan ini menggabungkan strategi dan kesederhanaan, contohnya permainan The Settlers of Catan. Pada permainan ini pemain dapat membangun suatu bangunan, sehingga pemain yang memiliki pembangunan paling hebat akan menjadi pemenang dari permainan. Contoh German Style Board Game adalah Puerto Rico.

\section{Race Game}

Inti permainan adalah pemain harus menggerakkan pion menuju ke titik akhir, dan yang tercepat adalah pemenangnya. Contoh Race Game adalah Pachisi atau yang sekarang dikenal dengan Ludo.

4. Roll-and-Move Game

Permainan ini menekankan pada dadu atau benda apapun yang dapat menghasilkan suatu angka secara acak sehingga menentukan langkah apa yang harus diambil pemain. Contoh Roll-and-Move Game adalah Monopoly.

5. Trivia Game

Permainan ini menekankan akan pengetahuan pemain dimana pemain diharuskan menjawab pertanyaan-pertanyaan yang bersifat umum ataupun dengan tema tertentu. Contoh Trivia Game adalah trivial pursuit.

6. Word Game

Permainan ini merupakan permainan yang mengolah dan berhubungan dengan kata-kata. Salah satu permainan word game paling terkenal adalah permainan Scrabble.

7. Wargame

Permainan ini merupakan sistem permainan yang metodenya meniru sistem operasi militer dengan aturan yang mirip perang sesungguhnya.

Berdasarkan jenisnya, peneliti akan mengembangkan media Board game yang menggabungkan Board game jenis German-Style Board Game atau Eurogames dan Trivia Game yang diberi nama Smart Land. Smart Land yang dikembangkan menggunakan strategi untuk menghasilkan suatu bentuk tertentu dengan model puzzle dan dilengkapi kartu pertanyaan sesuai dengan tema tertentu untuk memecahkan masalah sebagai sarana mengembangkan kemampuan berpikir kreatif.

\section{Kemampuan Berpikir Kreatif}

Berpikir kreatif merupakan suatu kegiatan mental untuk meningkatkan keaslian ide (originality), dan ketajaman pemahaman (insight) dalam mengembangkan sesuatu (generating) (Coleman \& Hammen, 1974; Sukmadinata, 2004). Berpikir kreatif memuat aspek ketrampilan kognitif dan metakognitif (Agres \& Wiggins, 2015; Lev \& Leikin, 2013). Ketrampilan tersebut antara lain ketrampilan mengidentifikasi masalah, menyusun pertanyaan, mengidentifikasi data yang relevan dan tidak relevan, produktif, menghasilkan banyak ide baru dan memuat disposisi yaitu bersikap terbuka, berani mengambil posisi/resiko, bertindak dan bersikap cepat (Agres \& Wiggins, 2015; Lev \& Leikin, 2013). Berpikir kreatif yaitu kombinasi dari berpikir logis dan berpikir divergen (Barnard \& Herbst, 2018; Ramlah \& Marlina, 2018). Ketika seseorang menerapkan kemampuan berpikir kreatifnya untuk memecahkan masalah, maka kemampuan berpikir divergen akan menghasilkan ide atau ide baru untuk memecahkan masalah. Sedangkan kemampuan berpikir logis melibatkan proses rasional dan sistematis untuk memeriksa dan memvalidasi ksimpulan dari pemecahan masalah yang dihasilkan (Siswono, 2010). 
Berpikir Kreatif berhubungan erat dengan kreatifitas. Kreatifitas adalah tindakan kontinu, sebagai proses menghasilkan sesuatu yang baru (Best \& Thomas, 2008; Runco \& Jaeger, 2012). Kreatifitas membuat seseorang dapat memahami sebuah masalah, mencari solusi-solusi yang mungkin, menarik hipotesis, menguji dan mengevaluasi, serta mengkomunikasikan hasilnya kepada orang lain (Torrance, 1995). Kreativitas muncul karena adanya kesempatan dan suasana kreatif untuk melakukan aktivitas kreatif dalam berkarya (Wahyudi et al., 2020).

Hasil kreativitas merupakan hasil kemampuan berpikir kreatif yang dilakukan oleh seseorang dalam rangka memecahkan masalah atau menghasilkan sesuatu yang baru dengan pendekatan baru, perspektif baru dengan banyak cara (McGregor, 2007) Hasil kreativitas yang merupakan hasil kemampuan berpikir kreatif merupakan tingkatan yang paling tinggi dalam proses kognitif (Mohanty, 2015).

Berdasarkan hasil kajian yang telah dilakukan, maka dapat diambil definisi dari kemampuan berpikir kreatif matematis yaitu kemampuan berpikir yang mengarah pada pemerolehan wawasan baru, pendekatan baru, perspektif baru, atau cara baru dalam memahami sesuatu masalah terkait dengan matematika yang meliputi aspek kelancaran, keluwesan, kebaruan, dan elaborasi hasil dari kreativitas seseorang. Definisi ini akan dipakai sebagai acuan penyusunan instrumen untuk mengukur kemampuan berpikir peserta didik.

\section{Model 3CM Learning}

Model 3CM (Cool-Critical-Creative-Meaningful) learning mulai dikembangkan tahun 2018 dan mulai dipublikasikan tahun 2019. Model 3CM learning merupakan model pembelajaran yang memberikan kesempatan belajar dengan melibatkan kerja otak kiri dan kanan (Wahyudi et al., 2019, 2020). Model pembelajaran yang tidak hanya memberikan kesempatan peserta didik berpikir menggunakan logika (otak kiri), tetapi juga memberikan kesempatan peserta didik mengembangkan kreativitasnya dengan memaksimalkan kerja otak kanan sebagai sumber intuisi, inisiatif, seni dan kreatifitas. Pembelajaran dimulai dengan menciptakan suasana yang menyenangkan melalui penyajian kejadian kontektual yang menarik dan menantang atau game tantangan sesuai topik yang akan dibahas $(\mathrm{Cool})$. Rasa senang ini akan membangun bahkan memperkuat sikap positif terhadap pelajaran/topik yang akan dipelajari. Keadaan ini akan memudahkan pengajar menaikan level berpikir peserta didik untuk memikirkan masalah dari kejadian kontektual yang diberikan serta mengkritisi masalah tersebut (Critical). Hirarki berpikir yang dimulai dengan kondisi hati yang senang ini, akan memungkinkan peserta didik menghasilkan pemecahan masalah buah pemikiran mereka (Critical). Hal ini menjadi modal untuk mengajak mereka memikirkan kemungkinan pemecahan masalah lain yang berbeda sebagai produk kreatif hasil kreativtas mereka (Creative). Hasil-hasil kreatif yang dihasilkan peserta didik menjadi dasar untuk merefleksikan apa yang mereka dapat saat proses belajar dan menemukan manfaat hasil tersebut dalam kehidupan mereka sehari-hari (Meaningful). Hal ini akan membantu peserta didik memaknai apa yang mereka dapatkan dalam rangka membentuk sikap baik (Meaningful). Belajar tidak hanya untuk mendapatkan pengetahuan tetapi harus memberikan kesempatan bagaimana membentuk sikap baik yang mampu membentuk karakter baik peserta didik. Hirarki belajar ini jika dilakukan terus menerus maka akan memberi kesempatan peserta didik berpikir dengan logika yang benar serta melibatkan intuisi, inisiatif, dan kretivitas mereka sehingga membentuk peserta didik yang kritis dan kreatif serta membentuk pribadi dengan karakter yang baik (Wahyudi et al., 2019, 2020)

\section{METODE PENELITIAN}

Penelitian ini merupakan jenis penelitian Research and Development (R\&D) dengan disain pengembangan ADDIE. Kegiatan pengembangan dilakukan dalam 5 tahapan yaitu: Analysis, Design, Development, Implementation, Evaluation.

Produk yang dihasilkan akan dilihat kevalidan (kelayakan), kepraktisan, dan efektivitasnya. Kevalidan pada produk dilakukan dengan menggunakan penilaian pakar. Penilaian pakar meliputi pakar materi, pakar media dan pakar pembelajaran. Uji pakar meggunakan angket dengan skala likert dengan rentang skor 1-4 dengan kriteria sangat kurang (1), kurang (2), baik (3) dan sangat baik (4). Hasil uji pakar digunakan untuk melihat kelayakan pada media Smart Land. Kepraktisan produk dilihat dari pemberian angket tertutup pada guru dan peserta didik. Sedangkan perbandingan hasil pretes dan postes dilakukan untuk melihat keefektifan media Smart Land. 
Pengembangan Media Smart Land Untuk Meningkatkan Kemampuan Berpikir Kreatif Dalam

Penerapan 3CM Learning Untuk ... (Wahyudi, Dian Nuryani, Yohana Setiawan)

Teknik analisis hasil pengembangan produk didasarkan pada hasil penilaian ahli materi dan ahli media dengan menggunkan persamaan berikut ini:

$$
\begin{array}{lll}
\mathrm{Xi}=\sum x & & \text { Keterangan : } \\
& \mathrm{Xi} & \text { : Skor rata-rata } \\
& \sum \mathrm{x} & \text { : Jumlah skor } \\
& n & \text { : Jumlah responden }
\end{array}
$$

Berikut ini adalah tabel untuk melihat kriteria kelayakan media.

Tabel 1. Kriteria Kelayakan Media

\begin{tabular}{cccc}
\hline Skor & Interval & Kategori & Konversi \\
\hline 4 & $3,25 \leq \mathrm{Xi} \leq 4,00$ & Sangat Baik & Layak \\
\cline { 1 - 3 } 3 & $2,5 \leq \mathrm{Xi}<3,25$ & Baik & \\
\hline 2 & $1,75 \leq \mathrm{Xi}<2,5$ & Kurang Baik & \multirow{2}{*}{ Tidak Layak } \\
\cline { 1 - 3 } 1 & $1 \leq \mathrm{Xi}<1,75$ & Sangat Kurang Baik & \\
\hline
\end{tabular}

Berdasarkan kriteria pada Tabel 1, Media Smart Land dikatakan layak untuk diujicobakan jika analisis data yang dihasilkan mendapat skor dengan rentang $2,5 \leq X<3,25$ atau 3,25 $\leq X \leq 4,00$ dari ahli materi maupun ahli media.

Uji kepraktisan dilakukan dengan melihat hasil respon peserta didik dan guru menggunakan angket tertutup. Hasil respon peserta didik dan guru dianalisis ke dalam bentuk kualitatif menggunakan skala Guttman, dengan kriteria penilaian pada Tabel 2 berikut:

Tabel 2. Kriteria Produk Uji Coba

\begin{tabular}{cccc}
\hline Skor & Interval & Kategori & Konversi \\
\hline 2 & $1<\mathrm{X} \leq 2$ & Ya & Layak \\
\hline 1 & $0<\mathrm{X} \leq 1$ & Tidak & Tidak Layak \\
\hline
\end{tabular}

Analisis data angket dari respon peserta didik yang dihasilkan dapat dinyatakan praktis jika memperoleh skor dengan rentang nilai $1<\mathrm{X} \leq 2$.

Uji efektivitas media Smart Land dilihat hasil perbandingan pre-test dan post-test, dengan menerapkan model untuk satu kelas dengan one group design. Hasil dari kedua tes tersebut selanjutnya di uji dengan Paired Samples T Test dengan software SPSS 22 for windows.

\section{HASIL DAN PEMBAHASAN}

\section{Hasil Penelitian}

Hasil dari penelitian ini dapat dijelaskan dalam tahapan pengembangan dengan disain ADDIE dalam 5 tahapan berikut ini.

\section{Analysis (Analisis)}

Tahap pertama dari pengembangan produk yang dilakukan adalah analisis kebutuhan. Analisis kebutuhan ini berguna untuk menentukan kebutuhan yang tepat sebagai solusi masalah yang dihadapi dalam hal ini terkait dengan kegiatan pembelajaran. Analisis kebutuhan dilakukan melalui wawancara dengan guru wali kelas III. Hasil yang didapatkan proses pembelajaran masih didominasi dengan penyampaian materi dengan ceramah, penugasan dan tanya jawab. Pembelajaran belum banyak memberi kesempatan peserta didik untuk mengembangkan kemampuan berpikir kreatif. Model pembelajaran yang digunakan belum sesuai dengan prinsip belajar dalam mengembangkan kemampuan berpikir kreatif. Selain itu media atau alat bantu pembelajaran belum mendukung pada aktivitas pembelajaran yang mampu meningkatkan kemampuan berpikir kreatif. Hal ini menyebabkan kemampuan berpikir kreatif peserta didik masih dalam kategori kurang. Perlu ada perubahan cara belajar dengan model pembelajaran yang sesuai dengan kebutuhan untuk meningkatkan kemampuan berpikir kreatif. Salah satu model yang bisa diterapkan adalah model 3CM learning karena model ini terbukti dapat meningkatkan kemampuan berpikir dan kreativitas peserta didik (Larasanti \& Prihatnani, 2021; Wahyudi et al., 2021). Selain itu juga diperlukan penyiapan media yang mendukung dalam aktivitas belajar untuk meningkatkan kemampuan berpikir kreatif dan sesuai dengan karakteristik 
peserta didik di kelas III. Tidak hanya aktif badan dengan bergerak kesana kemari namun juga aktif dalam hal berpikir kreatif. Untuk itu perlu dikembangkan media yang membuat mereka senang bermain tetapi juga mengembangkan kemampuan berpikir kreatif mereka. Salah satu media yang bida dikembangkan adalah media board game yang diberi nama Smart Land. Media Smart Land dirancang menjadi sebuah permainan yang dimainkan secara kelompok dalam pembelajaran dengan model 3CM learning. Media Smart Land memberikan kesempatan kepada peserta didik untuk berkompetisi, bekerja dalam tim dan belajar aktif agar kemampuan berpikir kreatifnya meningkat.

\section{Design (Perancangan)}

Tahap design dilakukan dengan membuat story board untuk menjelaskan garis besar permainan Smart Land yang akan dikembangkan. Story board menjelaskan secara runtut, dari tampilan board game, design kartu , puzzle, cara bermain dan aturan permainan pada media Smart Land. Setelah design selesai dibuat langkah kedua adalah implementsi dari story board ke dalam produk menggunakan aplikasi software CorelDraw X7. Proses design disesuaikan dengan karakteristik anak Sekolah Dasar untuk tampilan dan juga gambar-gambar yang digunakan. Untuk aturan main dalam media game ini dikembangkan sesuai prinsip game oleh Bell (Limantara et al., 2015).

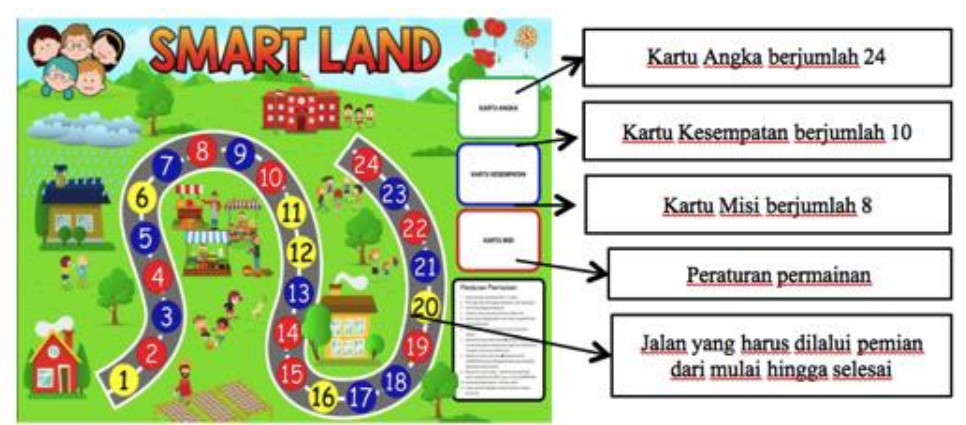

Gambar 1. Tampilan Board Game Smart Land

Board game pada media Smart Land dibuat dengan kombinasi warna hijau dengan gambar kegiatan yang biasa dilakukan sehari-hari. Board game dalam media Smart Land memiliki bagianbagian untuk mendukung permainan. Jalan bernomer menjadi lintasan pemain. Nomer pada jalan memiliki 3 warna yaitu kuning, merah dan biru. masin-masing warna memiliki perintahnya sendirisendiri. Jika pemain berhenti pada nomer warna kuning berarti hanya lewat, Jika pemain berhenti pada nomer warna merah maka dia mendapatkan kartu misi dan jika pemain berhenti pada nomer warna biru mendapat kartu kesempatan. Selain itu board game dalam media Smart Land juga memiliki tempat kartu yang ada di sebelah kanan. Sedangkan peraturan permaian ada pada bagian bawah kanan.

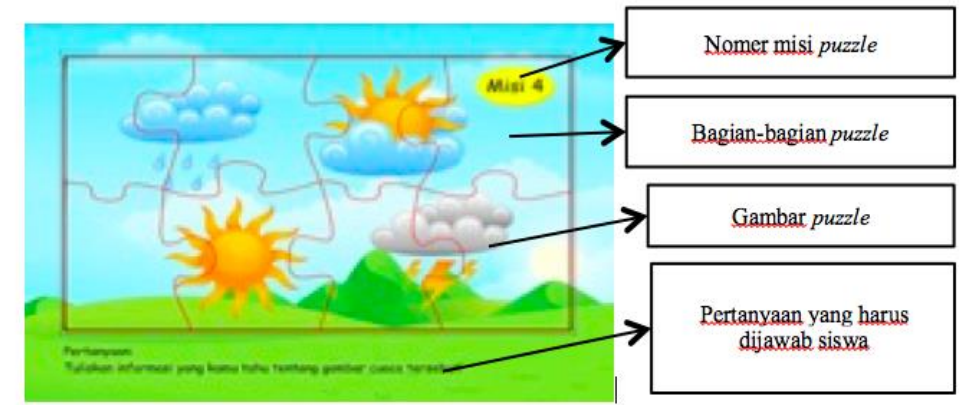

Gambar 2. Tampilan puzzle media Smart Land

Puzzle adalah salah satu permainan edukatif yang dapat mengasah kemampuan berpikir peserta didik. Mereka harus berpikir dengan cepat untuk dapat menyusun potongan-potongan gambar menjadi gambar yang logis. Puzzle di buat sebagai misi dalam media Smart Land. Peserta didik diajak berpikir kreatif disini. Tugas peserta didik ketika mendapatkan misi tidak hanya menyusun bagian puzzle menjadi gambar yang logis saja namun dalam misi puzzle ada pertanyaan yang harus diselesaikan oleh peserta didik dengan batasan waktu. 

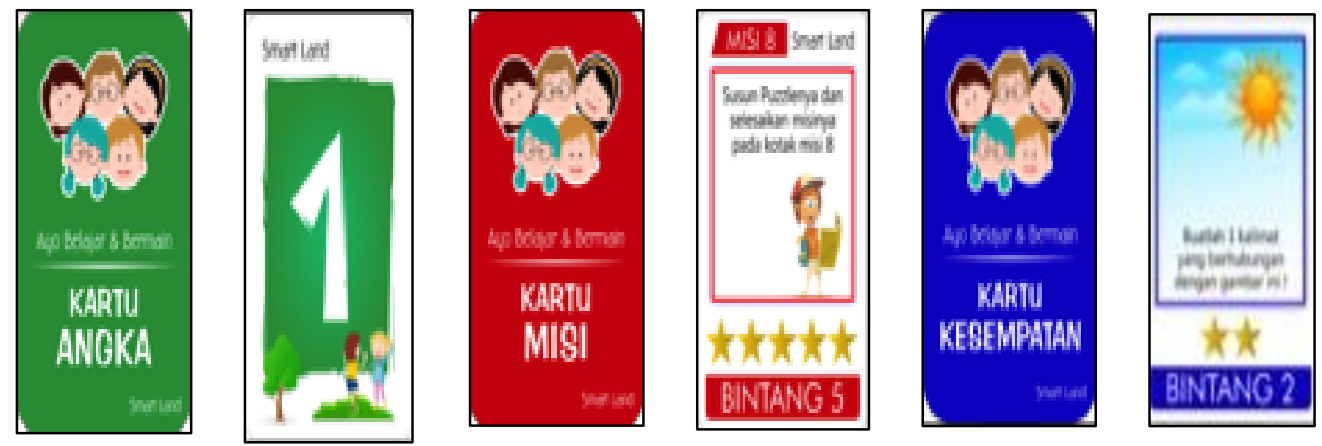

Gambar 3. Tampilan kartu media Smart Land

Media Smart Land memiliki 3 kartu yaitu kartu angka, kartu misi dan kartu kesempatan. masing-masing memiliki ketentuan. Kartu berwarna hijau adalah kartu nomer untuk menentukan kemana pemain akan berhenti, kartu berwarna merah adalah kartu misi untuk menentukan misi berapa yang mereka dapatkan. Kartu warna biru adalah kartu kesempatan kartu ini berisi pertanyaan yang harus dijawab oleh peserta didik.

\section{Development (Pengembangan)}

Pada tahap ini media yang sudah di design selanjutnya masuk pada tahap pemilihan bahan dan pencetakan. Pencetakan media dilakukan di percetakan outdoor agar mendapatkan hasil yang lebih baik. Setelah media selesai dicetak selanjutnya melakukan uji pakar. Perolehan nilai dari pakar materi yang ditinjau dari pembelajaran mendapatkan jumlah skor seluruhnya adalah 127 setelah dikonversikan dalam kategori kelayakan didapatkan skor 3,53 dari rentang skor 3,25 $\leq \mathrm{X} \leq 4,00$ yang dapat dinyatakan media Smart Land layak untuk diujicobakan di lapangan. Sedangkan perolehan nilai dari pakar madia mendapatkan jumlah skor seluruhnya adalah 76 setelah dikonversikan dalam kategori kelayakan didapatkan skor 3,61 dari rentang skor 3,25 $\leq \mathrm{X} \leq 4,00$ yang dapat dinyatakan media Smart Land layak untuk diujicobakan di lapangan. Namun pada media Smart Land masih ada beberapa bagian yang perlu dilakukan perbaikan, berikut ini hasil perbaikan media Smart Land. Revisi desain, tahapan revisi produk dilakukan setelah mendapatkan hasil evaluasi dari pakar materi dan media. Bagian yang mendapatkan saran perbaikan selanjutnya dilakukan revisi untuk kemudian diujicobakan dilapangan.

Tabel 3. Revisi Produk Berdasarkan Saran Ahli/Pakar

\begin{tabular}{l}
\multicolumn{1}{c}{ Saran } \\
\hline $\begin{array}{l}\text { a. Kalimat perintahnya menjadi: "Susun } \\
\text { puzzlenya dan selesaikan misinya pada } \\
\text { kotak misi 6. }\end{array}$
\end{tabular}

\section{Implementation and Evaluation (Implementation dan Evaluation)}

Implementasi produk dilakukan setelah produk diperbaiki sesuai rekomendasi dan persetujuan ahli. Implementasi produk media Smart Land dilakukan di kelas III SD Jatijajar 01. Untuk melihat kepraktisan implementasi produk media Smart Land, dilakukan pengukuran respon guru dan peserta didik terhadap pelaksanaan pembelajaran dengan media Smart Land menggunakan angket. Hasil yang didapatkan dari respon guru skornya 2 dengan kategori sangat baik sehingga layak digunakan. Sedangkan respon peserta didik sebesar 1,24 dengan kategori sangat baik sehingga layak digunakan. 
a. Saran pertanyaan "Susunlah puzzle ini termasuk puzzle segitiga-segitiga menjadi bentuk belah ketupat"

b. Saran petunjuk "Puzzle segitiga disusun agar pada sisi segitiga yang bersebelahan membentuk jawaban antara gambar dan bilangan pecahannya."
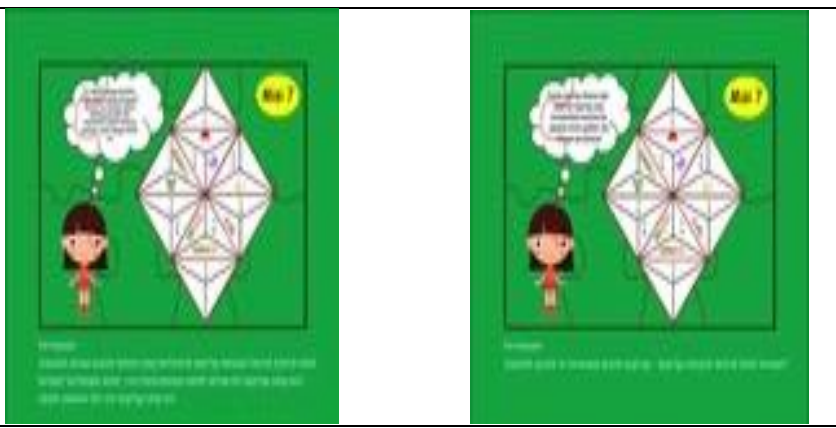

Selain pengukuran respon guru dan peserta didik, dilakukan juga observasi terhadap pelaksanaan pembelajaran dengan media Smart Land. Data ini digunakan untuk melihat keterlaksanaan pembelajaran dengan model yang telah diterapkan. Hasil observasi menunjukkan $100 \%$ dari langkahlangkah pembelajaran (sintak model) terlaksana dengan baik ditunjukkan dari skor hasil pengukuran 3,53 .

Untuk melihat efektifitas penggunaan media Smart Land dilihat dari hasil uji paired sample $t$ test hasil pre-test dan post-test. Berdasarkan hasil perhitungan dan uji hipotesis didapatkan nilai sig. (2tailed) adalah 0.000 atau kurang dari 0.05 sehingga dapat dikatakan ada perbedaan rata-rata hasil kemampuan berpikir kreatif yang signifikan antara hasil pre-test dan post-test seperti pada Tabel 4.

Tabel 4. Hasil uji Paired Samples Test

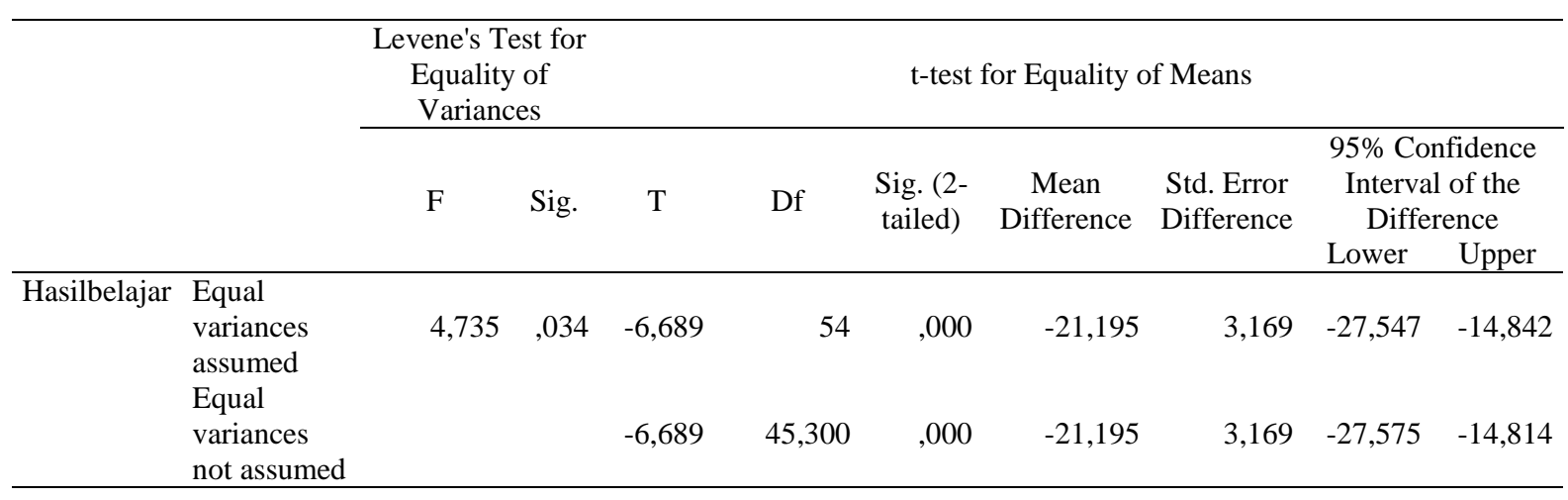

\section{Pembahasan}

Berdasarkan hasil penelitian yang telah dipaparkan maka pengembangan media board game Smart Land telah memenuhi tiga kriteria yaitu valid, praktis dan efektif. Hal ini ditunjukkan dari hasil penilaian pakar yang meliputi dua aspek yaitu kualitas media dan materi dalam media. Hasil yang didapatkan aspek media dengan skor 3,61 (kategori sangat baik) dan aspek materi dalam media dengan skor 3,53 (kategori sangat baik) sehingga produk layak digunakan (valid). Kepraktisan produk dilihat dari respon guru dan peserta didik terhadap produk dan implementasinya dalam pembelajaran. Berdasarkan hasil implementasi terbatas, skor angket dari respon guru sebesar 2 dengan kategori sangat baik. Sedangkan respon peserta didik didapatkan skor 1,24 dengan kategori sangat baik. Dengan dua hasil ini maka dapat dikatakan bahwa media Smart Land praktis digunakan dalam pembelajaran. Selain itu hasil observasi pembelajaran didapatkan skor 3,53 dengan kategori sangat baik, sehingga media dapat diimplementasi dengan baik. Berdasarkan hasil perhitungan dan uji hipotesis didapatkan nilai sig. (2-tailed) adalah 0.000 atau kurang dari 0.05 sehingga dapat dikatakan ada perbedaan rata-rata hasil kemampuan berpikir kreatif yang signifikan antara hasil pre-test dan post-test. Hasil ini juga didukung dari hasil observasi pembelajaran dan respon peserta didik. Dimana peserta didik terlihat antusias dan senang dalam belajar karena adanya media game Smart Land dan aktivitas tantangan yang ada di dalam game. Hal ini sesuai dengan hasil penelitian bahwa lingkungan belajar yang positif dan menyenangkan akan membuat peserta didik termotivasi dan kreatif untuk menghasilkan sesuatu yang bermanfaat serta mampu memecahkan masalah dengan baik (Fan \& Cai, 2020).

Misi-misi yang diberikan memberikan peluang peserta untuk mendapatkan tantangan dan berpikir untuk menyelesaikan misi tersebut dengan cara-cara yang berbeda. Kondisi inilah yang memungkinkan peserta didik dapat meningkatkan kemampuan berpikir kreatif sehingga daya 
Pengembangan Media Smart Land Untuk Meningkatkan Kemampuan Berpikir Kreatif Dalam

Penerapan 3CM Learning Untuk ... (Wahyudi, Dian Nuryani, Yohana Setiawan)

kreativitasnya meningkat. Kreativitas inilah yang memungkinkan peserta didik dapat menghasilkan penyelesaian masalah yang beragam dari setiap masalah yang diberikan. Kreativitas meningkat karena terjadi peningkatan kemampuan berpikir kreatif. Kreatifitas muncul karena ada suasana, lingkungan dan komunitas yang dikondisikan. Hal ini menunjukkan bahwa kreatifitas muncul karena adanya kesempatan untuk melakukannya (Wahyudi et al., 2021). Kreatifitas muncul karena ada suasana, lingkungan dan komunitas yang dikondisikan untuk melakukan sesuatu yang kreatif (Cahyati et al., 2018; C.-E. Huang, 2020; C.-H. Huang, 2016). Hal ini juga membuktikan bahwa kreatifitas merupakan kualitas integrasi dari seseorang dan menjadi modal seseorang untuk berkarya sesuai kreativitasnya (Khairullina et al., 2016). Hasil ini juga menunjukkan dampak dari peran guru dalam mengembangkan kemampuan berpikir kreatif sehingga kreativitas peserta didik dalam memecahkan masalah meningkat (As'ari et al., 2019). Dengan kemampuan tersebut peserta didik menghasilkan kreatifitas yang mengarah pada perolehan wawasan baru, pendekatan baru, perfektif baru atau cara baru dalam memahami suatu masalah yang meliputi aspek keluwesan, kebaruan dan elaborasi (Wahyudi et al., 2019)

\section{SIMPULAN}

Berdasarkan hasil penelitian dan pembahasan dapat ditarik simpulan bahwa media game Smart Land valid, praktis dan efektif digunakan dalam pembelajaran untuk meningkatkan kemampuan berpikir kreatif peserta didik. Peningkatan kemampuan berpikir kreatif mendorong peningkatan kreativitas peserta didik dalam menghasilkan pemecahan masalah yang beragam dari setiap masalah yang diberikan dalam bentuk game. Hasil ini dapat dilihat dari penilaian pakar media dengan skor 3,61 (kategori sangat baik) ahli materi dengan skor 3,53 (kategori sangat baik). Kepraktisan media game Smart Land dapat dilihat dari hasil angket respon guru dan peserta didik, dimana skor yang didapatkan 2 dan 1,24 dengan kategori sangat baik. Media Smart Land terbukti efektif digunakan dalam pembelajaran untuk meningkatkan kemampuan berpikir kreatif peserta didik. Hal ini terlihat dari hasil uji hipotesis yang menunjukkan adanya perbedaan rata-rata pada hasil pre-test dan post-test dan sig. (2tailed) 0,000 .

Berdasarkan hasil penelitian ini disarankan bagi para guru dapat membuat media pembelajaran yang lain dengan prinsip board game yang memungkinkan peserta didik dapat mengembangkan kemampuan berpikir kreatif dengan kegiatan yang asik dan menantang sesuai dengan prinsip 3CM learning.

\section{DAFTAR PUSTAKA}

Agres, K., \& Wiggins, G. A. (2015). Schematic processing as a framework for learning and creativity in CBR and CC.

Al-Tabany, T. I. B. (2011). Desain Pengembangan Pembelajaran Tematik Bagi Anak Usia Dini TK. RA \& Anak Usia Kelas Awal SD/MI, Jakarta: Prenadamedia Group.

As'ari, A. R., Kurniati, D., \& Subanji. (2019). Teachers expectation of students' thinking processes in written works: A survey of teachers' readiness in making thinking visible. Journal on Mathematics Education, 10(3), 409-424. https://doi.org/10.22342/jme.10.3.7978.409-424

Barnard, B., \& Herbst, D. (2018). Entrepreneurship, innovation and creativity: the creative process of entrepreneurs and innovators. https://ssrn.com/abstract=3195912

Best, B., \& Thomas, W. (2008). The creative teaching \& learning resource book. A\&C Black.

Cahyati, H., Muin, A., \& Musyrifah, E. (2018). Efektivitas Teknik SCAMPER dalam Mengembangkan Kemampuan Berpikir Kreatif Matematis Siswa. Journal of Medives : Journal of Mathematics Education IKIP Veteran Semarang, 2(2), 173. https://doi.org/10.31331/medives.v2i2.641

Coleman, J. C., \& Hammen, C. L. (1974). Contemporary psychology and effective behavior. Scott, Foresman.

Danarty, D. (2010). Fun Family Full Games Mudah, Murah, Menarik, Kreatif, Edukatif, Sekaligus Menyenangkan. In Yogyakarta: Penerbit Andi. 
Fan, M., \& Cai, W. (2020). How does a creative learning environment foster student creativity? An examination on multiple explanatory mechanisms. Current Psychology. https://doi.org/10.1007/s12144-020-00974-z

Fatah, A., Suryadi, D., Sabandar, J., \& others. (2016). Open-Ended Approach: An Effort in Cultivating Students' Mathematical Creative Thinking Ability and Self-Esteem in Mathematics. Journal on Mathematics Education, 7(1), 11-20.

Huang, C.-E. (2020). Discovering the creative processes of students: Multi-way interactions among knowledge acquisition, sharing and learning environment. Journal of Hospitality, Leisure, Sport \& Tourism Education, 26, 100237.

Huang, C.-H. (2016). Students' use of intuitive reasoning to decide on the validity of mathematical statements. American Journal of Educational Research, 4(14), 1025-1029.

Istiqomah, F., Rochmad, R., \& Mulyono, M. (2017). Mathematical Creative Thinking Ability of the Seventh Grade Students in Terms of Learning Styles to the Preview-Question-Read-ReflectRecite-Review (PQ4R) Learning. Unnes Journal of Mathematics Education, 6(2), 258-267.

Kadir, L., \& Satriawati, G. (2017). The implementation of open-inquiry approach to improve students' learning activities, responses, and mathematical creative thinking skills. Journal on Mathematics Education, 8(1), 103-114.

Kawuryan, S. P., Hastuti, W. S., \& Supartinah, S. (2018). The influence of traditional games-based and scientific approach-oriented thematic learning model toward creative thinking ability. Cakrawala Pendidikan, 1, 237921.

Khairullina, N., Bakhtizin, R., Gaisina, L., Kosintseva, T., \& Belonozhko, L. (2016). Development of Creative Activity of Students in the System of the Organizational Culture of the Modern University. International Journal of Environmental and Science Education, 11(4), 2171-2184.

Larasanti, R., \& Prihatnani, E. (2021). Pembelajaran Daring dengan Model Kolaboratif 3CM dan Tutor Sebaya untuk Meningkatkan Hasil Belajar dan Kreativitas. Scholaria: Jurnal Pendidikan Dan Kebudayaan, 11(3), 271-282.

Lev, M., \& Leikin, R. (2013). The connection between mathematical creativity and high ability in mathematics. Proceedings of the Eight Congress of the European Society for Research in Mathematics Education (CERME8), 1204-1213.

Limantara, D., Waluyanto, H. D., \& Zacky, A. (2015). Perancangan board game untuk menumbuhkan nilai-nilai moral pada remaja. Jurnal DKV Adiwarna, 1(6), 9.

Maharani, H. R., Sukestiyarno, S., \& Waluya, B. (2017). Creative thinking process based on wallas model in solving mathematics problem. International Journal on Emerging Mathematics Education, 1(2), 177-184.

McGregor, D. (2007). Developing thinking; developing learning. McGraw-Hill Education (UK).

Mohanty, A. (2015). Information processing and creative thinking abilities of residential and nonresidential school children: a pilot study. SAGE Open, 5(4), 2158244015611452.

Moma, L. (2017). Pengembangan kemampuan berpikir kreatif dan pemecahan masalah matematis mahasiswa melalui metode diskusi. Jurnal Cakrawala Pendidikan, 36(1), 130-139.

Navarrete, C. C. (2013). Creative thinking in digital game design and development: A case study. Computers \& Education, 69, 320-331.

Nuha, M., Waluya, S. B., \& Junaedi, I. (2018). Mathematical Creative Process Wallas Model in Students Problem Posing with Lesson Study Approach. International Journal of Instruction, 11(2), 527-538.

Ramlah, R., \& Marlina, R. (2018). Implementasi Teknik Visual Thinking Berbasis Pengoptimalan Fungsi Otak Kanan Dalam Pencapaian Komunikasi Matematis Siswa SMP. Sigma, 2(2), 5058. 
Pengembangan Media Smart Land Untuk Meningkatkan Kemampuan Berpikir Kreatif Dalam

Penerapan 3CM Learning Untuk ... (Wahyudi, Dian Nuryani, Yohana Setiawan)

Republik Indonesia. (2003). UNDANG-UNDANG REPUBLIK INDONESIA NOMOR 20 TAHUN 2003 TENTANG SISTEM PENDIDIKAN NASIONAL. https://pusdiklat.perpusnas.go.id

Republik Indonesia. (2016). Lampiran Standar Proses Permendikbud Nomor 22.

Rohmatin Apriliani, L., \& Suyitno, H. (2016). Unnes Journal of Mathematics Education Research KEMAMPUAN BERPIKIR KREATIF MATEMATIS BERDASARKAN KECEMASAN MATEMATIKA PADA PEMBELAJARAN CREATIVE PROBLEM SOLVING BERTEKNIK SCAMPER. http://journal.unnes.ac.id/sju/index.php/ujmer

Runco, M. A., \& Jaeger, G. J. (2012). The standard definition of creativity. Creativity Research Journal, 24(1), 92-96.

Rusman, M. P. (2017). Belajar \& Pembelajaran: Berorientasi Standar Proses Pendidikan. Prenada Media.

Sanaky, H. A. H. (2013). Media pembelajaran interaktif-inovatif. Yogyakarta: Kaukaba Dipantara.

Siswono, T. Y. E. (2010). Leveling Students' Creative Thinking in Solving and Posing Mathematical Problem. Indonesian Mathematical Society Journal on Mathematics Education, 1(1), 17-40.

Siswono, T. Y. E. (2011). Level of students creative thinking in classroom mathematics. Educational Research and Reviews, 6(7), 548-553.

Soebagio, M. F., Yuwono, E. C., \& Soewito, B. M. (2015). Perancangan Media Permainan Edukatif mengenai Kuliner dari Pemanfaatan Mangrove untuk Anak Usia 8-12 Tahun. Jurnal DKV Adiwarna, 1(6), 13.

Sternberg, R. J. (2005). Creativity or creativities? International Journal of Human-Computer Studies, 63(4-5), 370-382.

Sternberg, R. J. (2006). The nature of creativity. Creativity Research Journal, 18(1), 87.

Sternberg, R. J. (2012). The assessment of creativity: An investment-based approach. Creativity Research Journal, 24(1), 3-12.

Sternberg, R. J., \& Sternberg, K. (2016). Cognitive psychology: Nelson Education. Belmont, CA: Wadsworth.

Sukmadinata, N. S. (2004). Kurikulum \& Pembelajaran Kompetensi. Bandung: Kusuma Karya.

Tindowen, D. J. C., Bassig, J. M., \& Cagurangan, J.-A. (2017). Twenty-First-Century skills of alternative learning system learners. Sage Open, 7(3), 2158244017726116.

Torrance, E. P. (1995). The beyonders' in why fly. A Philosophy of Creativity. Norwood, NJ: Ablex.

Trnova, E., \& Trna, J. (2014). IMPLEMENTATION OF CREATIVITY IN SCIENCE TEACHER TRAINING. https://www.researchgate.net/publication/272746723

Vale, I., \& Barbosa, A. (2015). Mathematics creativity in elementary teacher training. Journal of the European Teacher Education Network, 10, 101-109.

Wahyudi, W., Waluya, S. B., Suyitno, H., \& Isnarto, I. (2020). The impact of 3CM model within blended learning to enhance students' creative thinking ability. Journal of Technology and Science Education, 10(1), 32-46. https://doi.org/10.3926/jotse.588

Wahyudi, W., Waluya, S. B., Suyitno, H., \& Isnarto, I. (2021). Schemata and creative thinking ability in cool-critical-creative-meaningful (3CM) learning. International Journal of Sustainability in Higher Education, 22(1), 1-28. https://doi.org/10.1108/IJSHE-06-2019-0198

Wahyudi, Waluya, S. B., Suyitno, H., \& Isnarto. (2019). Development of 3CM (cool-critical-creativemeaningful) learning model to increase creative thinking skill. Journal of Physics: Conference Series, 1321(2). https://doi.org/10.1088/1742-6596/1321/2/022063 